\title{
IMPACT OF QUENCH SEVERITY AND HARDNESS ON AISI 4137 USING ECO-FRIENDLY QUENCHANTS AS INDUSTRIAL HEAT TREATMENT
}

\author{
A. S. Adekunle', K. A. Adebiyi ${ }^{2}$ and M. O. Durowoju ${ }^{2}$ \\ ${ }^{1}$ Mechanical Engineering Department, University of Ilorin, Ilorin, Nigeria \\ ${ }^{2}$ Mechanical Engineering Department, \\ Ladoke Akintola University of Technology, Ogbomoso, Nigeria. \\ E-mail: adebayo@unilorin.edu.ng \\ Phone: +234 (0) 8033591465
}

\begin{abstract}
The rate of heat extraction, hardness, and severity of quenching of both edible and nonedible bioquenchants for industrial heat treatment was investigated using AISI 4137 medium carbon steel. Results showed that both the maximum and minimum cooling rates occurred in the nucleate boiling stage and were strongly dependent on the viscosity and saponification number. The peak cooling rates of Jatropha oil, groundnut oil, melon oil, sheabutter oil, palmkernel oil, and palm oil were greater than that of mineral oil. The quench severities of Jatropha, sheabutter, and groundnut oil are higher with an H-factor of 5.93,6.00, and 6.14, respectively. High heat transfer coefficient of 1583, 1180, and $1024 \mathrm{~W} / \mathrm{m}^{2} \mathrm{~K}$ were obtained for Jatropha oil, groundnut oil, and melon oil; whereas sheabutter oil, palmkernel oil, palm oil, and mineral oil have heat transfer coefficient of $1001,971,828$, and $589 \mathrm{~W} / \mathrm{m}^{2} \mathrm{~K}$, respectively. For all the quenchants, the hardness of steel is increased with an increase in the austenite heating temperature.
\end{abstract}

Keywords: Heat transfer; bioquenchants; cooling rate; quench severity; Jatropha.

\section{INTRODUCTION}

Quenching operations belong to the process of heat treatment, during which highly intensive and dynamic heat transfer occurs at the surface of the body. The determination of the temperature field in the cooled body requires unity conditions of the heat conduction equation. Comparisons of different quenchants in the heat-treatment processes of steels are of great usefulness in order to achieve desired hardness, strength or toughness, and to minimize the possibility of the occurrence of quench cracks due to the evolution of residual stresses (Totten \& Maurice, 1997). The choice of effective quenching medium following heat treatment is critical to ensuring the achievement of the desired mechanical properties; hence, the selection of a quenchant depends on the quench sensitivity of a particular grade of steel and on the severity of the quench medium (Buczek \& Telejko, 2004; Feng \& Tahir, 2008). There are three stages of quenching. The first is the vapor blanket, in which vapor film surrounding the component acts as an insulating blanket reducing the heat flow from the component subjected to quenching. The second stage is known as the nucleate boiling stage, where the vapor film collapses and high heat extraction rates are achieved. The third stage, known as the convective cooling stage, begins when the temperature of the metal surface is reduced below the boiling point of the quenching liquid; the cooling rate is low during this stage (Totten, Tensi, \& Lainer, 1999; Fernandes \& Prabhu, 2008). 
The severity of quenching or the cooling power of a quench medium is estimated by measuring the thermal response of a heated probe brought into contact with it. It is a measure of the ability of a quenchant to extract heat from a sample during quenching and it depends on viscosity, temperature, contamination, and agitation. The cooling potential of quenching media is a critical factor in heat-treatment processes because of its contribution to attaining the minimum hardenability requirement of the part or section being heat-treated (Canale, Fernandes, Agustinho, Totten, \& Farah, 2005). A cooling curve analysis method is most useful for assessing the cooling characteristics of a quenching medium (Prabhu \& Imtiyaz 2011). Quench severity can be determined by measuring the Grossmann hardenability factor $\mathrm{H}$, and the heat transfer coefficients. Heat transfer coefficient $h$ is defined as the ratio of interfacial heat flux to the temperature drop across the interface. The lumped heat capacitance method (LHCM) and the Grossmann method are generally used to measure the heat coefficient at the quenchant/probe interface and to assess the severity of the quenching. In both methods, heat flux $\mathrm{q}$ and/or the heat transfer coefficient $\mathrm{h}$ are calculated directly from the measured cooling curve data. The LHCM assumes a uniform probe temperature during the cooling (Protsidim, Ya Rudakova, \& Shevemeta, 1988). If the probe temperature is uniform, the heat loss $Q$ from the probe is equal to the decrease in the internal energy of the probe. Thus:

$$
Q=h A\left(T_{p}-T_{q}\right)=C_{p} \rho V\left(\frac{d T_{p}}{d t}\right)
$$

where $h$ is the heat transfer coefficient on the probe surface, $A$ is the surface area of the probe, $T_{p}$ is the probe temperature, $T_{q}$ is the quenchant temperature, $C_{p}$ is the specific heat of the probe material, $\rho$ is the specific density of the probe material, $V$ is the volume of the probe material, $t$ is the time, and $d T / d t$ is the cooling rate of the probe. The heat flux can be estimated by using Eq. (1), as given by Goryushin, Istomin, Ksenofontov, Marsel, and Yu Shevchenko (1999):

$$
q=h\left(T_{p}-T_{q}\right)=\left(\frac{C_{p} \rho V}{A}\right) \frac{d T_{p}}{d t}
$$

The accuracy of the cooling rate calculated from the measured cooling curve data determines the precision of the estimated heat flux or heat transfer coefficient. In the Grossmann technique, a hardenability factor $H$ is defined as given in Eq. (3) by Fernandes and Prabhu (2008):

$$
H=\frac{\bar{h}}{2 k}
$$

The present study was carried out to assess the heat transfer rate and quench severity of various bioquenchants and conventional quench media using the Grossman and LHCM techniques for characterizing media with low and high severity of quenching. 


\section{EXPERIMENTAL DETAILS}

The vegetable oils used for this work were purchased at the local Nigeria Southwestern markets and were characterized and used in as-purchased condition. The vegetable oils purchased include Jatropha oil, groundnut oil, melon oil, sheabutter oil, palmkernel oil, and palm oil. The quenching performance of these oils was compared with one commercially available mineral oil designated as quintolubric 888-46 (conventional slow oil). The chemical structure of the bioquenchants used in this work was characterized by fluid viscosity, which was measured at $40{ }^{\circ} \mathrm{C}$ according to ASTM D445-06 standard tests. The fatty acid ester composition of the vegetable oil was determined by a gas chromatographic analysis procedure, using methyl ester derivatives of the different vegetable oils prepared, by using a Model Hp 6890 gas chromatograph equipped with a flame ionization detector (FID) set to $300{ }^{\circ} \mathrm{C}$ and a split injection system ratio of $1: 30$ at $280{ }^{\circ} \mathrm{C}$.

The cylindrical probes of $0.37 \% \mathrm{C}$ steel specimens of $13.5 \mathrm{~mm}$ diameter and 70 $\mathrm{mm}$ length were fitted with a type-K thermocouple to their geometric center (Figure 1). They were heated in an electric furnace at the rate of $25^{\circ} \mathrm{C} / \mathrm{min}$ to a temperature of 850 $\pm 3{ }^{\circ} \mathrm{C}$, and soaked at that temperature for about 1 hour. The heights of these probes were five times their diameters to ensure heat transfer in the radial direction. The thermocouple was inserted in a hole of diameter $3 \mathrm{~mm}$ drilled in the top surface of the probe, and care was taken to ensure a tight fit and good contact. The heated specimens were transferred laterally, manually and rapidly (under $2 \mathrm{~s}$ ), into a rectangular quench bath containing $1000 \mathrm{~mL}$ of the bioquenchants to be tested under static conditions. The probe temperature and cooling times were captured using an SD card data logger digital thermometer Model MTM-380SD in order to establish a cooling temperature versus time curve. The hardness of the specimen was determined using a microhardness tester LM700AT. The steel material was cut into small pieces and ground to a smoother surface, following which the piece was mounted on a Vickers hardness tester under an applied load of $490.3 \mathrm{mN}$ for a period of $10 \mathrm{~s}$ and the depth of penetration of the indenter was recorded.

\section{RESULTS AND DISCUSSION}

\section{Chemical properties}

The analysis of the oils by gas chromatography using methyl ester derivatives shows that the vegetable oils used possess triglyceride structures, which are completely saturated, monounsaturated, diunsaturated, and triunsaturated (Table 1). The two most common saturated fatty esters in the vegetable oils used for this study are palmitic and stearic, whereas the monounsaturated ester is oleic and the diunsaturated ester is linoleic. In addition, the chemical compositions of the steel material used for the investigation are shown in Table 2. 
Table 1. Composition percentage of fatty acids present in sample of vegetable oils.

\begin{tabular}{|c|c|c|c|c|c|c|c|c|}
\hline \multirow{2}{*}{$\begin{array}{l}\text { Vegetable } \\
\text { oils }\end{array}$} & \multicolumn{6}{|c|}{ Saturated acids } & \multirow[b]{2}{*}{$\begin{array}{l}\text { Oleic } \\
\text { C18:1 }\end{array}$} & \multirow[b]{2}{*}{$\begin{array}{r}\text { Linolei } \\
\text { C18:2 } \\
\end{array}$} \\
\hline & $\begin{array}{c}\text { Decanoate } \\
\text { C10:0 }\end{array}$ & $\begin{array}{l}\text { Lauric } \\
\text { C12:0 }\end{array}$ & $\begin{array}{c}\text { Myristic } \\
\text { C14:0 }\end{array}$ & $\begin{array}{c}\text { Palmitic } \\
\text { C16:0 }\end{array}$ & $\begin{array}{l}\text { Stearic } \\
\text { C18:0 }\end{array}$ & $\begin{array}{c}\text { Arachidic } \\
\text { C20:0 }\end{array}$ & & \\
\hline Palm oil & - & - & 0.76 & 36.50 & 3.69 & 1.03 & 45.66 & 12.36 \\
\hline Palm kernel oil & 3.57 & 50.37 & 17.08 & 8.98 & 8.55 & - & 9.23 & 2.21 \\
\hline Groundnut oil & - & - & - & 13.75 & 9.99 & 1.19 & 39.27 & 32.91 \\
\hline Melon oil & - & - & - & 17.02 & 20.77 & - & 11.00 & 49.26 \\
\hline Shea butter oil & - & - & - & 4.62 & 74.56 & 1.24 & 18.84 & 0.74 \\
\hline Jatropha oil & - & - & - & 48.34 & 19.81 & 3.68 & 31.85 & 20.26 \\
\hline
\end{tabular}

Table 2. Chemical composition (wt\%) of the steel used.

\begin{tabular}{lllllclclc}
\hline $\mathrm{C}$ & $\mathrm{Si}$ & $\mathrm{S}$ & $\mathrm{P}$ & $\mathrm{Mn}$ & $\mathrm{Ni}$ & $\mathrm{Cr}$ & $\mathrm{Mo}$ & $\mathrm{V}$ & $\mathrm{Cu}$ \\
\hline 0.37 & 0.23 & 0.06 & 0.05 & 0.79 & 0.12 & 0.10 & 0.02 & 0.003 & 0.26 \\
\hline $\mathrm{W}$ & $\mathrm{As}$ & $\mathrm{Sn}$ & $\mathrm{Co}$ & $\mathrm{Al}$ & $\mathrm{Pb}$ & $\mathrm{Ca}$ & $\mathrm{Zn}$ & $\mathrm{Fe}$ & \\
\hline 0.003 & 0.006 & 0.006 & 0.01 & -0.007 & -0.002 & 0.0001 & 0.004 & 97.95 & \\
\hline
\end{tabular}

\section{Cooling Rates}

Both the maximum and minimum cooling rate occurred in the nucleate boiling stage of $250-800{ }^{\circ} \mathrm{C}$ (Figure 1). For the edible bioquenchant oils, i.e., groundnut oil, melon oil, palmkernel oil, and palm oil, the maximum cooling rates were 74.6, 64.7, 61.3, and $52.3{ }^{\circ} \mathrm{C} / \mathrm{s}$ for temperatures of $644,617,550$, and $707^{\circ} \mathrm{C}$, respectively. For the nonedible bioquenchants, such as Jatropha and sheabutter oil, the peak cooling rates were 100 and $63.2{ }^{\circ} \mathrm{C} / \mathrm{s}$ for temperatures of 628.6 and $459.8^{\circ} \mathrm{C}$, respectively.

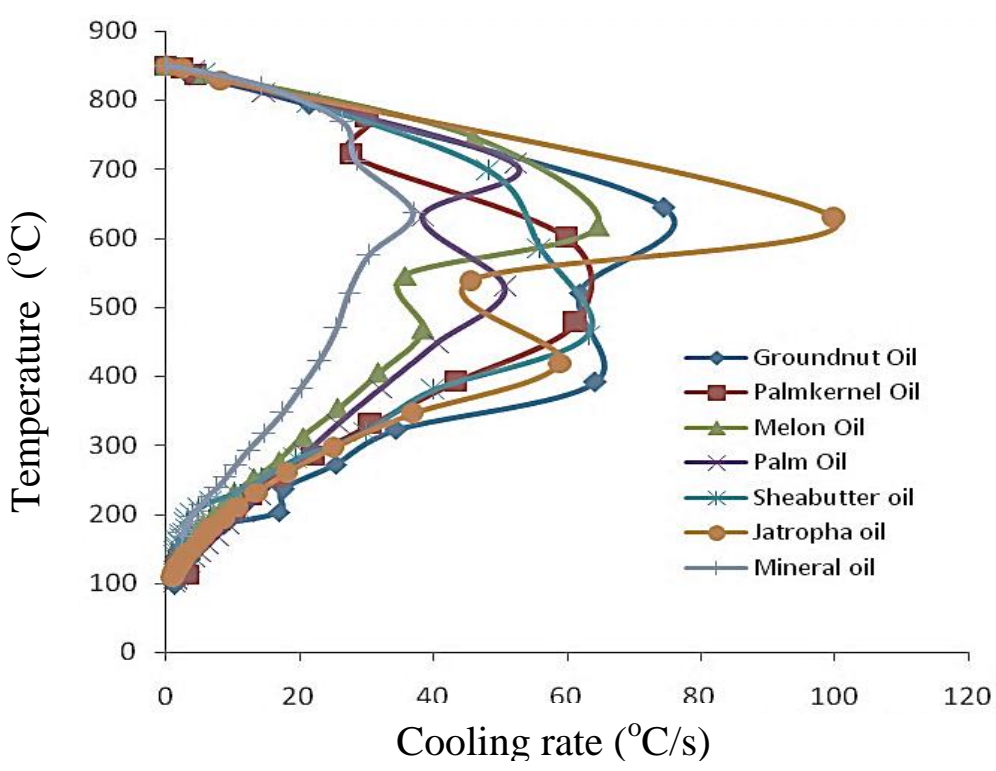

Figure 1. Cooling rates for various bioquenchants.

The minimum cooling rate for Jatropha oil was $59^{\circ} \mathrm{C} / \mathrm{s}$ at a corresponding temperature of $419^{\circ} \mathrm{C}$; mineral oil and sheabutter oil showed no minimum cooling rate. The cooling rate for mineral oil was $37.1{ }^{\circ} \mathrm{C} / \mathrm{s}$ at a temperature of $637{ }^{\circ} \mathrm{C}$. The period of occurrence of the peak cooling rate for melon oil, palm oil, and Jatropha oil was $6 \mathrm{~s}$ 
from the start of quenching, whereas for sheabutter and mineral oil it was $10 \mathrm{~s}$. The cooling rate was higher in Jatropha oil than in all other quenchant oils used. In all the quenchants, the cooling rate was found to be strongly dependent on the viscosity of the quench oil and on the saponification number. The higher the viscosity, the lower the cooling rate and the lower the saponification number, the higher the cooling rate. The cooling rates were determined to be in the following order:

Jatropha oil > Groundnut oil > Melon oil > Sheabutter oil > Palmkernel oil > Palm oil > Mineral oil.

\section{Heat Transfer Coefficient and Heat Flux}

Using the cooling curve data to determine the time-dependent heat transfer coefficient by LHCM and time-averaged heat transfer coefficient by the Grossman method, high heat transfer coefficients of 1583,1180 , and $1024 \mathrm{~W} / \mathrm{m}^{2} \mathrm{~K}$ were obtained for Jatropha, groundnut oil and melon oil. Sheabutter oil, palm kernel oil, palm oil, and mineral oil have heat transfer coefficients of $1001,971,828$, and $589 \mathrm{~W} / \mathrm{m}^{2} \mathrm{~K}$, respectively (Figure 2). The peak heat transfer coefficient of all bioquenchants was higher than the conventional mineral oil, which has a heat transfer coefficient of $589 \mathrm{~W} / \mathrm{m}^{2}$. The heat transfer coefficients were found to be highly dependent on the viscosity and acid value of the quench media, and the value increases with a decrease in percentage of acid value and with an increase in percentage of moisture content. Higher heat transfer coefficients were found with lower viscosity oils, such as Jatropha oil, groundnut oil, and melon oil, which have viscosities of $52.6,40.5$, and $35.6 \mathrm{~mm}^{2} / \mathrm{s}$, respectively. The temperatures at which the peak heat transfer coefficient occurs for all quenchants was in the nucleate boiling region for sheabutter oil, groundnut oil, mineral oil, palm oil, Jatropha oil, melon oil, and palmkernel oil, having values of $698,644,637,631,629,617$, and $601{ }^{\circ} \mathrm{C}$, respectively.

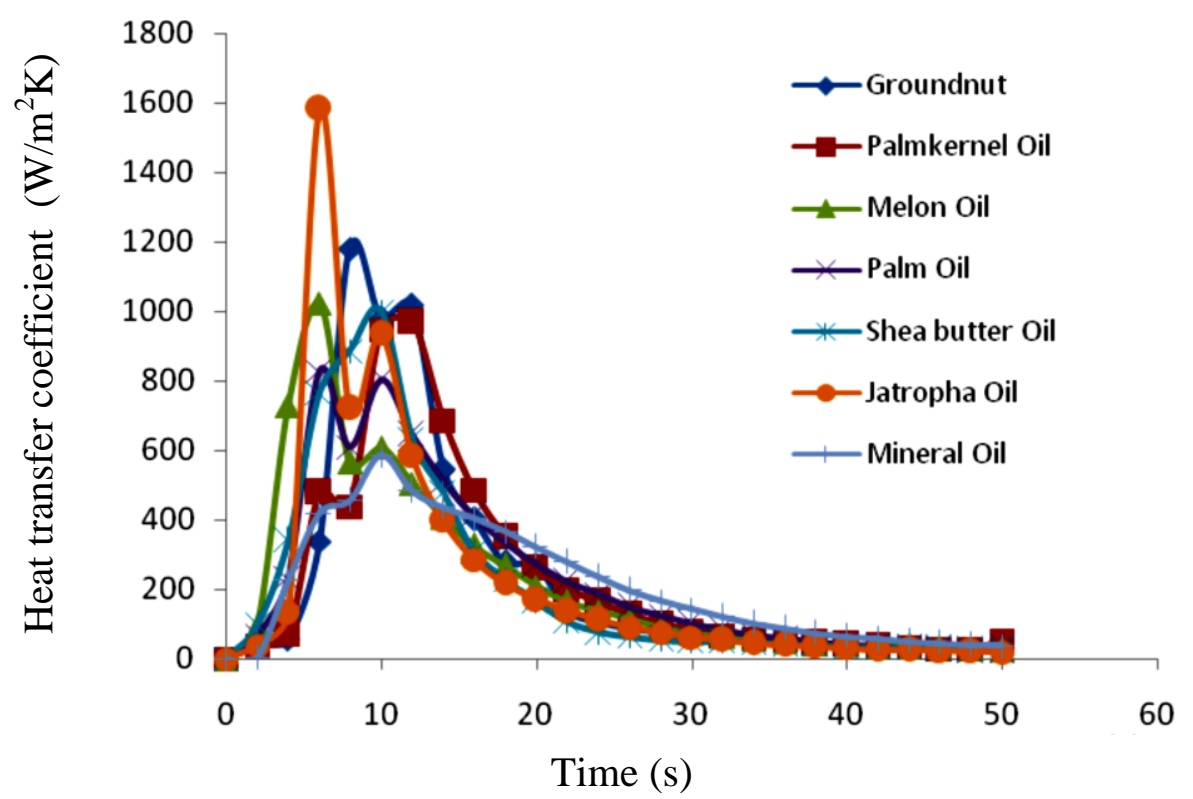

Figure 2. Variation of heat transfer coefficient of various quenching media for steels. 
The flux values for all quench media are low during the initial quenching time owing to the insulating effect of the vapor blanket (Figure 3). However, the duration of the existence of the vapor blanket stage was longer for bioquenchant media compared with the conventional mineral oil. The maximum heat flux of $948 \mathrm{~kW} / \mathrm{m}^{2}$ was obtained for Jatropha oil, whereas sheabutter oil has the lowest peak heat flux of $512 \mathrm{~kW} / \mathrm{m}^{2}$. The heat fluxes obtained for all bioquenchant media are higher than that of mineral oil (356 $\mathrm{kW} / \mathrm{m}^{2}$ ). The bioquenchants with higher viscosity offer greater resistance to the motion of vapor bubbles during the nucleate boiling stage and thereby, reduce the supply of cold liquid to the heated surface. This results in the lower peak heat flux transients during quenching of the steel probe.

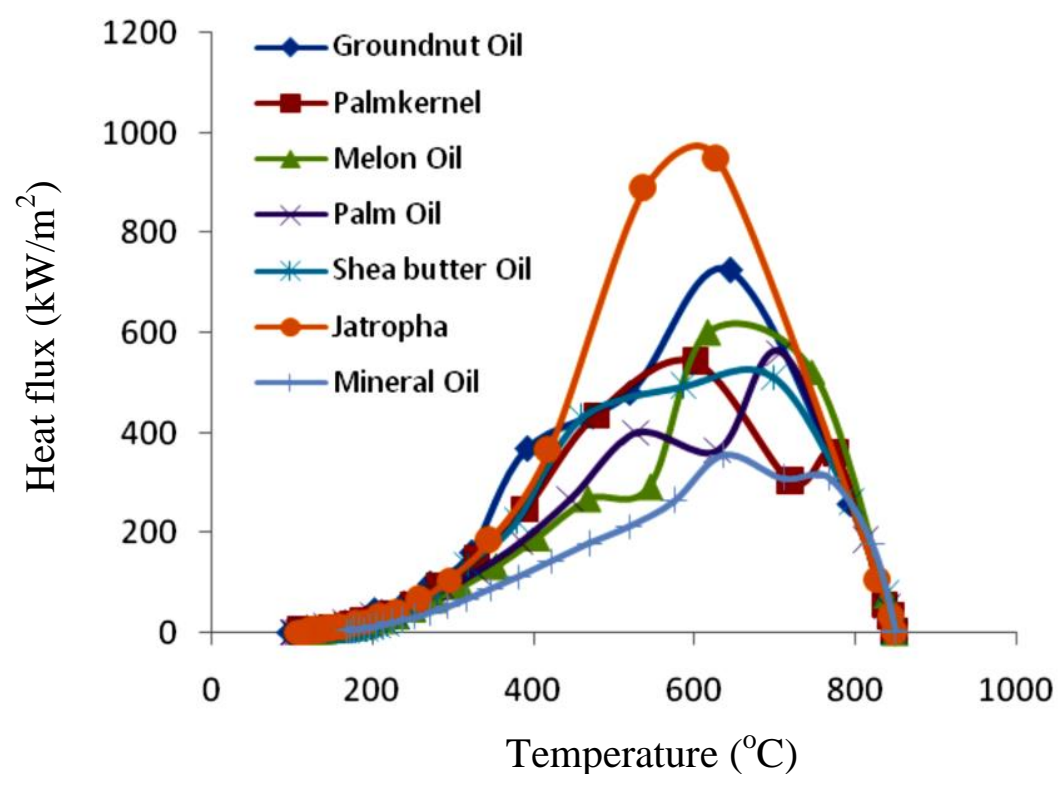

Figure 3. Variation of heat flux for various quenchants.

\section{Severity of Quench Media}

The biot number determined for the quenchants showed that for all the oils the biot number is very small and less than unity (Figure 4). The Grossmann quench severity (H) was calculated from experimental data and the values obtained showed that the quench severity of groundnut oil, sheabutter oil, and Jatropha oil were nearly the same with a value of $6.0 \mathrm{~m}^{-1}$ (Figure 5). Palm oil and conventional mineral oil had the lowest quench severity of $4.0 \mathrm{~m}^{-1}$. However, palmkernel oil and melon oil exhibited quench severity values of 5.2 and $4.7 \mathrm{~m}^{-1}$, respectively. The quench severities of the bioquenchants used were found to be related directly to the biot number; the higher the biot number, the higher the quench severity. The decreasing quench severity of the bioquenchants was determined to be in the following order:

Groundnut oil $\geq$ Sheabutter oil $\geq$ Jatropha oil $>$ Palmkernel oil $>$ Melon oil $>$ Palm oil $>$ Mineral oil. 


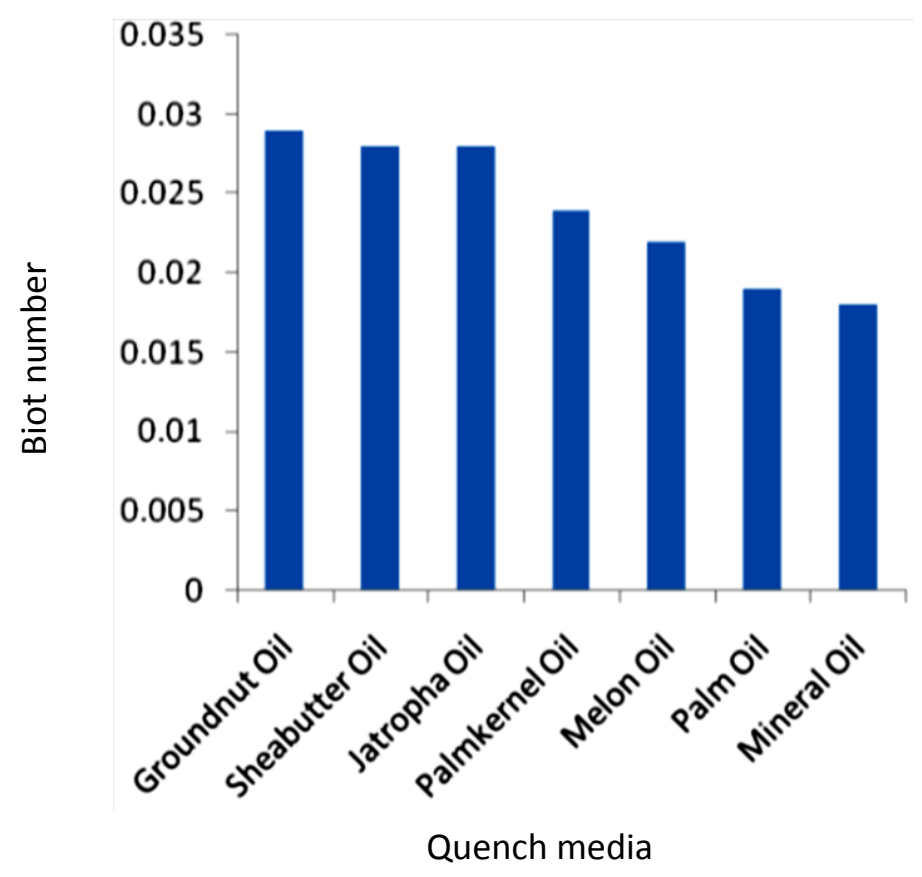

Figure 4. Biot number for different media.

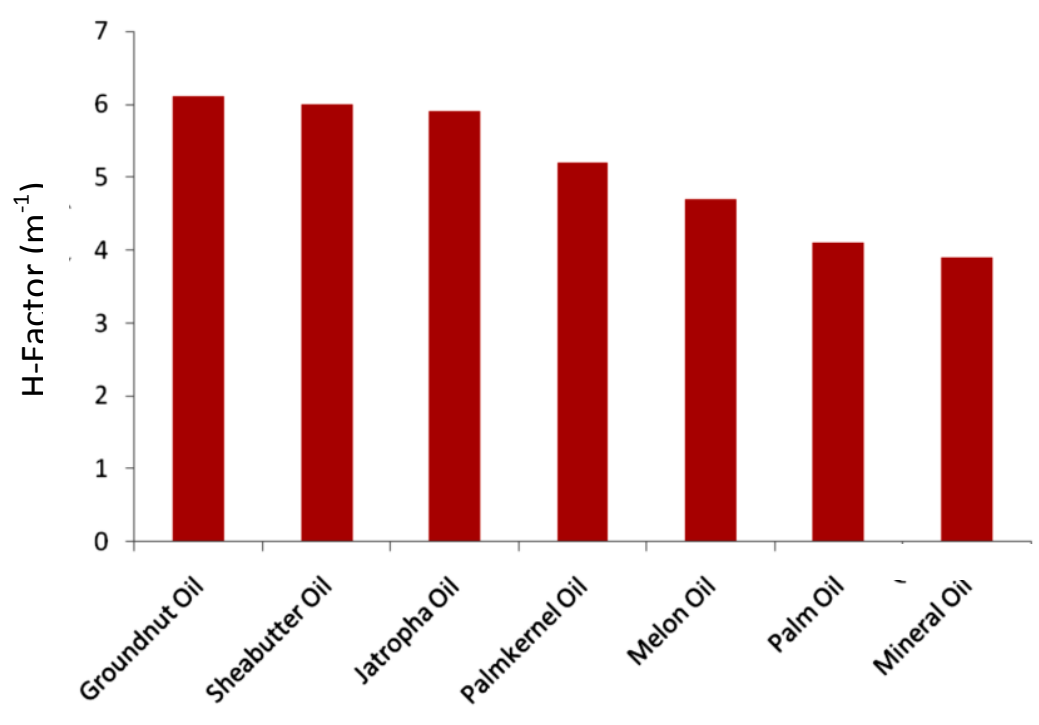

Quench Medium

Figure 5. Grossman H-factor of various media.

\section{Hardness}

The hardness value increases as the austenite heating temperature increases for all the quenchants (Figure 6). Melon oil, palm oil, sheabutter oil, and palmkernel oil gave steel hardness values of $657,649,642$, and $609 \mathrm{H}_{v}$, respectively, at $950{ }^{\circ} \mathrm{C}$, which was three times that of the as-received steel material with a hardness value of $208 H_{v}$. However, Jatropha oil and conventional mineral oil resulted in low hardness values of 394 and 404 $H_{v}$. The hardness attained by the steel in the quenchants was related directly to the percentage values of the oleic and linoleic esters (unsaturated acid); the higher the percentage of unsaturated acid, the higher the hardness. The heat-treated steel material 
exhibited different elongation in each bioquenchants, even at the same heat-treatment temperature (Figure 7). Jatropha oil, sheabutter oil, palmkernel oil, palm oil, and mineral oil all caused an increase in the elongation of the steel as the austenite temperature increased; thus, making the material more ductile and elastic. However, quenching with melon oil and groundnut oil caused the elongation of the steel material to decrease as the austenite temperature increased, thereby making the material more brittle. This was because of the very high percentage value of linoleic ester (C18:2), which was more than $20 \%$.

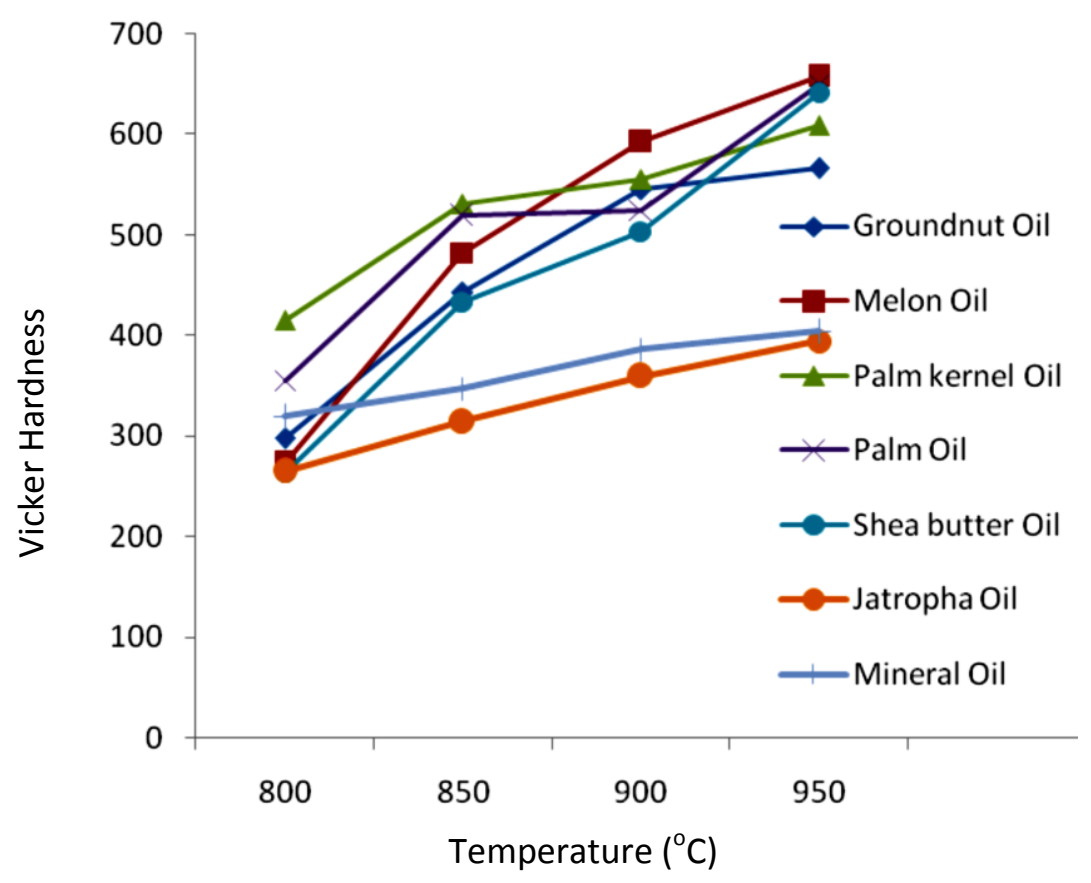

Figure 6. Variation of steel hardness in bioquenchants.

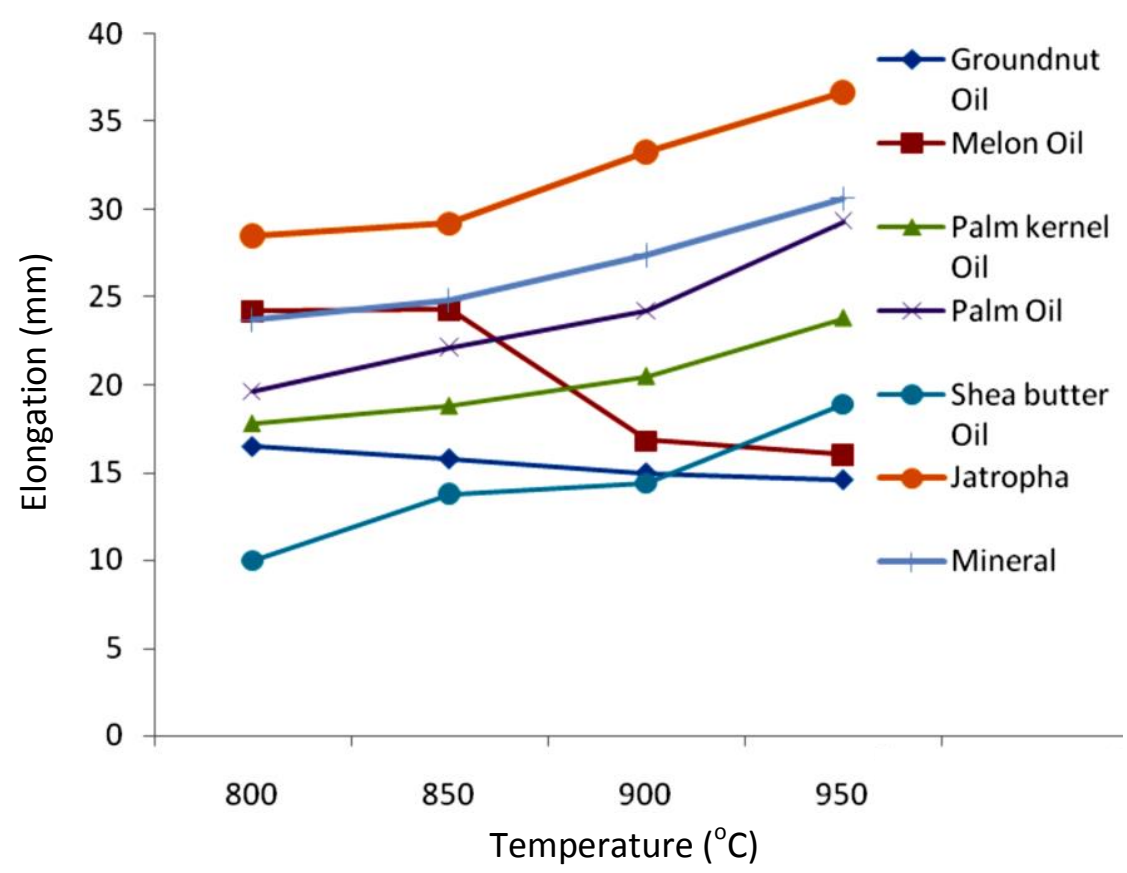

Figure 7. Steel elongation in different bioquenchants. 


\section{CONCLUSIONS}

Among the vegetable oils, the highest heat transfer coefficient and cooling rate was obtained for Jatropha oil, whereas the lowest heat transfer coefficient and cooling rate was obtained for palm oil. A higher heat transfer coefficient was found with lower viscosity oils and similarly, the heat flux during quenching was influenced by the viscosity. Cooling rate was found to be dependent strongly on the viscosity of the quench oil and on the saponification number. Melon, palmkernel, sheabutter, groundnut, and palm oil caused high hardness during quenching, whereas Jatropha and conventional mineral oil gave low hardness. Melon and groundnut oil caused brittleness when used for quenching; however, Jatropha, sheabutter, palmkernel, palm oil, and conventional mineral oil caused ductility and elasticity of the steel material during quenching. In general, excellent hardening properties were obtained with locally available vegetable oils. Hence, these oils are more suitable than mineral oil as quenching media in the hardening process. Based on the heat flow parameters, the hardness, and elongation properties, palm oil, sheabutter oil, palmkernel oil, and mineral oil could be used as slow-quenching media, whereas Jatropha oil, groundnut oil, and melon oil could be used has fast-quenching media.

\section{REFERENCES}

Buczek, A., \& Telejko, T. (2004). Inverse determination of boundary conditions during boiling water heat transfer in quenching operation. Journal of Materials Processing Technology, 155-156, 1324 -1329.

Canale, L. C. F., Fernandes, M. R., Agustinho, S. C. M., Totten, G. E., \& Farah, A. F. (2005). Oxidation of vegetable oils and its impact on quenching performance. International Journal on Materials and Product Technology, 24, 101-125.

Feng, C., \& Tahir I. K. (2008). The effect of quenching medium on the wear resistance of a Ti-6Al-4V alloy. Journal of Material Science, 43, 788-792.

Fernandes, P., \& Prabhu, K. N. (2008). Comparative study of heat transfer and wetting behavior of conventional and bioquenchants for industrial heat treatment. International Journal of Heat and Mass Transfer, 51, 526-538.

Goryushin, V.V., Istomin, N.N., Ksenofontov, A.G., Marsel, A.V., \& Yu Shevchenko, S. (1999). Quenching of ball-bearing steels and bearing parts in polymer medium UZSP-1. Metal Science and Heat Treatment, 41(2), 47-51.

Prabhu, K. N., \& Imtiyaz, A. (2011). Comparison of Grossmann and lumped heat capacitance methods for assessment of heat transfer characteristics of quench media. International Heat Treatment and Surface Engineering, 5, 41- 46.

Protsidim, P. S. Ya Rudakova, N., \& Shevemeta, B. K. (1988). Hardenability in steels prediction by calculation. Metal Science and Heat Treatment, 30, 86-88.

Totten, G. E. \& Maurice, A. H. (1997). Steel heat treatment handbook. Marcel Dekker, Inc.

Totten, G. E., Tensi, H. M., \& Lainer, K. (1999). Performance of vegetable oils as a cooling medium in comparison to a standard mineral oil. Journal of Materials Engineering and Performance, 8(4), 409-416. 